\title{
NUESTRO NORTE ES EL SUR: A BUSCA DA AUTONOMIA, OS DESAFIOS DA INTEGRAÇÃO REGIONAL E A CHINA
}

Ingrid Sartia aProfessora Titular de Ciência Política, Universidade Federal do Rio de Janeiro.

Rio de Janeiro, RJ, Brasil. E-mail: ingrid.sarti@gmail.com

Orcid: 0000-0002-4892-0362

Marcos Costa Limab

- Professor Titular do Departamento de Ciência Política, Universidade Federal de Pernambuco.Recife,PE, Brasil.E-mail:marcosfcostalima@gmail.com

Orcid: 0000-0002-3831-7631

Milton Bragattic

'Doutor em Relações Internacionais e Ciências Sociais, Universidade de Bologna e Universidade Nova de Lisboa.Bologna, Itália.E-mail: miltonbragatti@gmail.com

Orcid: 0000-0003-1176-2556 http://dx.doi.org/10.1590/0102-175210/113

\section{Introdução}

Aos trinta anos da assinatura do Tratado de Assunção, ${ }^{1}$ o Mercosul se consolida como bloco regional, ainda que em um período de ascensão do conservadorismo e de crise sanitária, política, social, cultural e econômica que assola todo o continente sul-americano. Entretanto, trata-se de um Mercosul desarticulado e sob risco de perder os avanços conquistados ao longo dos anos, pois parece aguardar

1 Argentina, Brasil, Paraguai e Uruguai assinaram o Tratado de Assunção que instituiu o Mercosul em 26 de março de 1991. 
a definição de novos rumos de recuperação ou recriação de uma agenda tão ampla quanto a integração do início do século XXI, que tantos avanços propiciou e que de tantas críticas foi alvo.

$\mathrm{Na}$ academia, assim como na política, o tema da integração permanece controverso na transdisciplinaridade de uma literatura acadêmica ainda distante de esgotar o debate entre as distintas concepções do regionalismo no continente. Basicamente, sem abordá-lo em texto breve como este, o debate contrapõe o regionalismo centrado em políticas comerciais na abertura de mercado e o regionalismo voltado para o desenvolvimento econômico e social e o fortalecimento de políticas regionais de inclusão social e redução das assimetrias regionais. ${ }^{2}$ A disputa entre as concepções preserva, no entanto, o ponto de partida consensual de que a integração nunca é apenas econômica, jamais é automática ou exclusivamente técnica e é sempre um processo político, histórico e territorialmente contextualizado (Sarti, 2011; 2014). "Na realidade, nosso norte é o sul"3, como disse o pintor Joaquín Torres García (tradução livre, 1941).

A trilha conceitual que seguimos sugere uma conexão entre autonomia, intergovernabilidade e democracia, três rotas inseparáveis para o acesso à análise do regionalismo periférico do sul. Destacamos a agenda progressista entre os anos de 2005 e 2015, ressaltando o protagonismo da política externa brasileira. Vale recordar que o "giro à esquerda" teve sequência na eleição de Luiz Inácio da Silva no Brasil no Brasil - 2003 -, Néstor Kirchner na Argentina 2003 -, Tabaré Vázquez no Uruguai - 2005 -, Evo Morales na Bolívia - 2006 -, Michelle Bachelet no Chile - 2006 -, Daniel Ortega na Nicarágua - 2006 -, Rafael Correa no

\footnotetext{
2 A literatura sobre esse debate é vasta. Para uma síntese, ver Riggirozzi e Tussie (2018).

3 No original: "En realidad, nuestro norte es el sur".

4 Ou "maré rosa", como na denominação de Panizza (2006).
} 
Equador - 2007 -, Fernando Lugo no Paraguai -2008 - e Mauricio Funes em El Salvador - 2009. ${ }^{5}$

Os governos que oscilavam entre políticas social-democráticas e expressões mais radicalizadas foram emblemáticos na implantação de políticas sociais de combate à pobreza, dentre as quais se destacam os processos da Cooperação SulSul (CSS), cujo efeito mobilizador e transformador era ainda muito incipiente. Foi sem dúvida relevante que o continente tivesse vivenciado, na década de 1990, crises políticas, econômicas e sociais agravadas pelas políticas neoliberais, que não apenas deixaram transparente a insatisfação da população com os regimes democráticos vigentes, como também confirmaram que as demandas por governos mais inclusivos e participativos não eram atendidas (Fukushima, 2019). No caso do projeto de regionalismo e a CSS, vale frisar que estamos tratando do projeto implementado pelos governos progressistas da América do Sul, cujas características se distinguem de outros projetos, como o da União Europeia, e até mesmo das tentativas integracionistas que o antecedem no continente latino-americano. Embora inovador, é incompleto, e sua natureza política, explicitada como escolha, foi orientada para a superação do lugar de periferia do sistema ao qual a região esteve atada desde seus primórdios. O projeto, assim, reafirma a natureza não só geopolítica, mas também política da integração ao associar seu êxito a um desenvolvimento econômico, social e cultural como requisito para um novo equilíbrio entre norte e sul, em uma ordem global que se pretendia multipolar.

\section{Autonomia, intergovernabilidade e democracia}

De modo singular, a aspiração à integração sul-americana tem sua origem justamente na oposição à condição de periferia

\footnotetext{
5 Tal cenário despertou a atenção de longa lista de cientistas sociais e políticos do exterior (Panizza, 2006; Roberts, 2008; Weyland, 2009) que, dentre outros motivos, buscaram entender os fatores explicativos de tais ascensões e as diferenças desses governos de esquerda quanto às suas administrações.
} 
e submissão aos interesses da potência hegemônica. O tema remonta, então, a um passado distante, com destaque no repertório das grandes utopias libertárias que denunciavam o aniquilamento da identidade coletiva e a subsunção de seus povos primitivos à dominação exercida pelo poder colonial, desde Bolívar aos anos 1920, principalmente, com Mariátegui (1928; Bruckmann, 2011). Mas, até hoje a integração é uma categoria presente no imaginário de superação da colonialidade, preservada ao longo dos séculos e sob a perspectiva eurocêntrica da modernidade que se instalou no continente, como bem descreveu Quijano (2005). Nos termos que sintetiza Gonçalves (2017), a perspectiva da autonomia é entendida como "aquela dos que se preocupam com as desigualdades sociais e com a injustiça social... É a preocupação dos que não se conformam em permanecer na periferia do sistema internacional" (p. 55).

Logo, historicamente, a autonomia que se busca como condição de desenvolvimento não é meramente uma refe178 rência utópica, mas um instrumento de superação de um sistema profundamente desigual, como tão bem descrito por Furtado e Prebisch (2000). Se a busca por autonomia foi sempre uma constante na estratégia de sair do lugar periférico que coube ao continente na divisão internacional do capital, as estratégias, contudo, foram diversas, bem como os contextos em que foram aplicadas. ${ }^{6}$

Como traço da singularidade do regionalismo sul, cabe observar sua origem diversa. Na contramão do regionalismo europeu, o Sul emerge alinhado à potência hegemônica na reconstrução de sua economia no pós-guerra, mesmo que com ressalvas por parte de autoridades estadunidenses em relação tanto à União Europeia (UE) quanto ao Mercosul

${ }^{6}$ Em que pese o reconhecimento de uma vocação autonomista do continente, é longa e controversa a lista de estudos indispensáveis para a compreensão dos distintos significados atribuídos à autonomia em diferentes períodos governamentais. De Puig (1980) a Jaguaribe (2008; 2017), passando, dentre outros, por Samuel Guimarães (2002), Cesar Guimarães (2008); Hurrell (2013), Vigevani e Cepaluni (2007) e Visentini (2005). 
de que ambos os blocos proporcionariam maior autonomia a suas regiões (Kissinger, 2001). Não obstante, ao sul do Equador parece persistir uma tendência a considerar a experiência europeia como um tipo ideal weberiano, o que acaba por distanciar a realidade analisada. Por exemplo, um aspecto apresentado como deficiência estrutural do sul em relação ao norte é a intergovernabilidade que nos caracteriza, um contraponto ao supranacionalismo europeu.

Assim, enquanto no sul a relação entre governos articula os processos de integração dos Estados, o fortalecimento das instituições é mais vulnerável do que sob a organização dos interesses supranacionais, o que é plausível. Porém, essa visão não se coaduna com a realidade histórica e política da América do Sul, que é regida pelo presidencialismo. O desafio é justamente fortalecer as instituições de integração no âmbito de políticas econômicas e sociais governamentais que se consolidem nos processos autonomistas de todos os Estados partes. Além disso, o grau de êxito será dado pelos índices dos resultados das políticas que reduzam desigualdades sociais e assimetrias regionais, garantindo os direitos de circulação dos povos.

O contraste com a UE é forte em termos de modelo de intergovernabilidade vis a vis supranacionalidade. Nesse sentido, Riggirozzi e Tussie (2018) apontam chaves para ler o regionalismo sul-americano no arranjo próprio com que buscam o fortalecimento do Estado, a regulamentação do mercado e a gestão da autonomia. As autoras apontam como característica de intergovernabilidade um paradoxo na forma de desenvolvimento regional da América do Sul:

[...] este não foi concebido como restrição ao nacionalismo, mas como um conjunto de instituições que potencializam em vez de limitar as decisões nacionais... uma modalidade de governança intergovernamental que, sem supranacionalidade, busca reforçar alguns aspectos de espaços de política. (Riggirozzi e Tussie, 2018, p. 7) 
Dentre os espaços da política, ganha relevância no sul o requisito da democracia como instrumento da articulação interna e externa dos Estados em regionalismo, que se define pela meta de redução das desigualdades sociais e o combate às profundas assimetrias no continente. Se a democracia esteve sempre presente na concepção do Mercosul, ${ }^{7}$ ela ganha relevo na gestão dos governos progressistas que invocavam a criação de uma cidadania regional como fator de fortalecimento da integração. O perfil de um Mercosul social e participativo não se restringia ao êxito na esfera comercial nem na coordenação de políticas macroeconômicas, mas implicava construir espaço para conter temas e questões esquecidos, como direitos humanos, meio ambiente, cultura, juventude, agricultura familiar, população originária e outros (Martins, 2021). Em suma, houve a valorização da democracia, que permanece como o crucial desafio, "crucial porque está vinculada às possibilidades de inventar um novo modelo econômico e social', nas palavras de Marco Aurélio Garcia (2017).

Nesta ocasião, vale identificar alguns traços de um projeto democrático de cooperação e redução das assimetrias que - mesmo interrompido - inovou e transpôs fronteiras políticas, econômicas, culturais e sociais. Refletir sobre as lições deixadas por ele nos parece uma forma de contribuir para a consolidação de um olhar regional próprio.

\section{Uma integração ampliada}

O projeto político de integração da América do Sul, ocorrido nas primeiras décadas do século XXI, abrigava duas vertentes que, simultaneamente, completavam a estratégia de busca de independência do centro do capitalismo e

\footnotetext{
7 O ex-ministro Celso Amorim relembra o objetivo de consolidação da democracia quando os presidentes Sarney e Alfonsin embarcaram no projeto de crescente associação entre as duas maiores economias da região. Depois de longos períodos de ditadura militar, a paz era condição para o êxito do Mercosul, que surgiria no Tratado de Assunção (Amorim, 2020)
} 
de um mundo mais próximo da multipolaridade. A primeira era voltada para uma estratégia continental de integração, enquanto a outra, referida como relações Sul-Sul, dirigia-se para a cooperação internacional com as potências médias ou emergentes. Foi um projeto sustentado que, em 2005, rejeitou a proposta da Área de Livre Comércio das Américas (ALCA) e promoveu a união de governos progressistas no abraço a um projeto integrador e autônomo para a região.

Quando o Mercosul comemorou seus vinte anos de existência, pareceu-nos relevante resgatar a natureza política do processo (Sarti, 2011). Tratava-se, então, de uma concepção ampliada, simultaneamente econômica, política, social e cultural de integração, que abrangia aspectos como territorialidade e que consolidava uma infraestrutura que garantia a integração física do continente, desde uma rede de energia elétrica, estradas, ferrovias e telecomunicações até a promoção do conhecimento, dos direitos de cidadania e da circulação dos povos no que se referia à educação, saúde, ciência, tecnologia, cultura e instituições. Ademais, envolvia o direito ao trabalho e demandava novas formas de pensar a educação e a institucionalização - por exemplo, um desempenho criativo das universidades e dos parlamentos. Incluía também iniciativas de produção e circulação da cultura — do artesanato às tecnologias midiáticas —, de acordo com os interesses dos povos da região. A meta, em suma, era obter uma integração solidária que não só reconhecesse como também operasse para reduzir as assimetrias. Aqui, a criação do Fundo para a Convergência Estrutural do Mercosul (FOCEM), de caráter estratégico e especificamente destinado para a redução das assimetrias no bloco, foi expressiva da nova intencionalidade integradora.

Gradualmente, foram criados espaços institucionais de participação social de cunho setorial - educação, saúde, trabalho e direitos - com iniciativas como o Instituto Social do Mercosul (ISM), Somos Mercosul e as cúpulas sociais 
desenvolvidas com o objetivo explícito de promover a participação da sociedade organizada no processo decisório do bloco. Destacaram-se as iniciativas dos conselhos, criados no âmbito do Mercosul e adotados em larga escala pelo governo brasileiro, que visava o diálogo e a participação de setores organizados da sociedade. Lamentavelmente, contudo, é justamente no âmbito da institucionalidade do Mercosul que se encontram os problemas mais nítidos de uma proposta voltada para resolver o déficit democrático da integração, como concluiu Morgante (2009), ao enfatizar a insuficiência das iniciativas institucionais da integração vis $a$ vis a dinâmica e a amplitude das redes e organizações ativas na região.

Além das fronteiras do Mercosul, o projeto, com protagonismo brasileiro, chegou a promover um importante mecanismo de cooperação internacional, os BRICS (Brasil, Rússia, Índia, China e África do Sul). Surpreendente, o êxito obtido foi resultado da vontade política de muitos governos do continente de criar de um órgão do porte da União de Nações Sul-Americanas (Unasul) ${ }^{8}$ em dezembro de 2008 (Nery, 2021; Carvalho, 2018; Bragatti, 2016). Os BRICS abrangiam a implantação de conselhos setoriais destinados a exercer um papel chave na condução de questões relevantes para o desenvolvimento da região, como o Conselho de Defesa Sul-Americano (CDS), Conselho Energético SulAmericano (CES), Conselho Sul-Americano de Infraestrutura e Planejamento (COSIPLAN) e o Conselho de Educação, Cultura, Ciência, Tecnologia e Inovação (COSECCTI).

O CDS, implantado em 2008, foi essencial para o redesenho de uma região soberana que não se define por tensões internas interestatais, mas que foi sempre considerada uma área sob influência da potência hegemônica

8 Vale observar que a Unasul compreendia 390 milhões de habitantes e um Produto Interno Bruto (PIB) regional próximo a 3,9 trilhões de dólares. 
(Bragatti, 2019). A memória da participação dos Estados Unidos nas ditaduras do século XX e eventos como o golpe de Estado em Honduras (2009) bem como a presença da Quarta Frota dos Estados Unidos nas águas do continente americano e os avanços militares norte-americanos na região sob pretexto de combater o narcotráfico, foram episódios que demonstraram a necessidade dos governos regionais se preocuparem com a defesa da soberania do continente e dos recursos naturais (Fuccille, Bragatti e Leite, 2018; Bragatti, 2020).

Cabe ainda mencionar a área da saúde, cujo protagonismo foi marcado pelo Instituto Sul-Americano de Governo em Saúde (ISAGS), órgão criado em 2008, com sede no Rio de Janeiro, que contava com a participação dos doze países do continente e o mecanismo pelo qual a Unasul se dedicava à saúde pública do continente como fator constitutivo da integração regional. Apesar de ter sido um marco no fomento à governança sul-americana em saúde, o ISAGS foi extinto em 2019. Enfrentando a fragilidade de uma institucionalidade desafiadora e incipiente em termos de cooperação sistêmica, como observa Fuccille (2018), a Unasul foi foco do processo destrutivo que atingiu as iniciativas bemsucedidas de autonomia. Mais especificamente, o célere aniquilamento da Unasul foi seguido do golpe que depôs a presidente brasileira Dilma Rousseff, em 2016.

Entretanto, outras iniciativas importantes como a proposta de transformar o Parlamento do Mercosul (Parlasul) em um órgão de representantes eleitos por sufrágio universal em cada um dos Estados-parte não vingou (Mariano, 2011). Mais graves, porém, foram os obstáculos que impediram a implementação do Banco do Sul, que deveria ter tido o protagonismo do financiamento da integração (Carvalho, 2018).

Embora tão próxima no tempo, tal experiência parece mais remota diante do enfraquecimento a que foi submetida pelos ditames da ordem hegemônica do capitalismo 
global na contenção de governos e partidos que buscavam caminhos alternativos para a América Latina. O projeto, interrompido pouco mais de dez anos depois, foi destituído de seu caráter de autonomia global.

No âmbito da integração, a política externa brasileira altiva e ativa do governo, sob a formulação de Celso Amorim, até então ministro das Relações Exteriores do Brasil, Samuel Pinheiro Guimarães, diplomata, e Marco Aurélio Garcia, assessor intelectual, marcou uma política internacional de inédita colaboração multipolar e criatividade, mas que foi bruscamente interrompida. Os últimos anos expuseram o recuo da diplomacia brasileira dentro e fora da região, o que já seria suficiente para situar o país em uma rota de regressiva inserção internacional. Alertando para a prioridade da recuperação do Brasil da inserção equilibrada do país e da região no mundo, Celso Amorim (2020, p. 10) aponta a tarefa imediata: "retirar nosso país do abismo tenebroso em 184 que estamos afundados". Um golpe, sabemos, nunca é um raio caído do céu azul, como já alertava Marx (2011), é sempre urdido no tempo e seu principal responsável - o capitalismo financeiro - não costuma aparecer como protagonista do espetáculo. Não somente, a interrupção do projeto SulSul, sacramentado em quase toda a região sul-americana, registra o momento de uma derrota do projeto autonomista regional enquanto também revela uma estratégia agressiva de retomada da hegemonia do sistema. ${ }^{9}$

Não será demais insistir que, assim como as relações internacionais de cooperação, a integração não pode ser entendida como mera questão técnica-administrativa ou restrita aos desígnios macroeconômicos, posto que está sempre

\footnotetext{
9 A oposição de amplos setores das classes dominantes não é aqui considerada somente fruto de uma conjuntura específica, mas de uma envergadura continental e até mesmo internacional de tentar aniquilar a influência da esquerda de modo definitivo. A estratégia de obstrução dos sistemas políticos democráticos, construídos a partir das transições democráticas dos anos 1980, indica a ampliação dos conflitos pelos recursos econômicos e sociais.
} 
sujeita aos condicionantes do poder e vulnerável às variações das vontades políticas determinantes nas gestões governamentais. Portanto, as seguintes observações sustentam nossa abordagem dos critérios de avaliação dos processos de autonomia e das instituições de integração no continente: (1) sua natureza política democrática, já que fazer escolhas e definir e colocar em prática as iniciativas são decisões dos Estados e de seus governantes; (2) a perspectiva integradora em busca da autonomia regional modifica as diretrizes do protagonismo da política externa e da diplomacia em cada governo, com ampla margem de atuação; (3) a multidimensionalidade é constitutiva de todo o processo de integração democrática, posto que dela se chega ao fluxo de trocas e se amplia a colaboração por áreas distintas.

Cabe ressaltar a importância da relação dos processos de integração regional com a disputa pelo poder global, com especial atenção para o ascenso da China no continente e sua franca disputa com os Estados Unidos, que nos leva a refletir sobre seus efeitos na região.

\section{A ascensão e a gradual aproximação chinesa na América Latina}

Partimos aqui da premissa de que o processo regressivo do Mercosul, a partir da recente retomada dos governos de direita, está relacionado ao que hoje vem se configurando como uma "nova Guerra Fria” que se estabelece entre a China e os Estados Unidos da América (EUA). Quando os EUA descuidaram de seus interesses na América Latina, por motivos de uma maior preocupação diplomática com o Oriente Médio e a Ásia, a região, que até os anos 1990 mantinha uma relação privilegiada com a potência norteamericana, estabeleceu novas relações econômico-comerciais com a China que prosperam vertiginosamente.

O governo do presidente estadunidense Joe Biden, em seus primeiros meses, anunciou na reunião do Grupo 
dos Sete (G7) um plano ambicioso para competir com a Iniciativa Belt and Road da China, oferecendo uma alternativa que, segundo a Casa Branca, teria o aval de seus colegas do G7 e envolveria centenas de bilhões de dólares em investimentos em infraestrutura no mundo em desenvolvimento (The Economist, 2021). A iniciativa chinesa, também chamada de "nova rota da seda", se estende até a América do Sul com projetos como o megaporto de Chancay, no Peru, que teve um investimento inicial de US $\$ 1,3$ bilhão e pode transformar a pequena cidade agrícola e pesqueira de Chancay, a partir de 2024, em um $h u b$ regional que poderia redefinir as linhas do comércio marítimo no Pacífico Sul (Torrico, 2021).

O aprofundamento dos laços da China com a América Latina reduziu a dependência econômica da região com relação aos Estados Unidos e coincidiu com o período do chamado regionalismo pós-liberal ou pós-hegemô186 nico, como apontam Legler, Turzi e Tzili-Apango (2020). No entanto, os autores não encontraram evidências de que a China tenha diretamente apoiado os processos políticos autonomistas regionais ou necessariamente reforçado uma governança regional autônoma. Ao contrário, o país não demonstrou predileção ideológica com relação aos governos, preferindo o desenvolvimento de relações com instituições multilaterais regionais de natureza eminentemente econômica (Legler, Turzi e Tzili-Apango, 2020, p. 44).

É nosso objetivo destacar as características da expansão chinesa e os avanços na cooperação com "o gigante chinês", que incluíram até mesmo a assinatura de projetos de transferência de tecnologia da China para o Brasil em 2010 (Cunha, 2017). Vale relembrar que a China "trabalha na expansão de um consenso fundado sobre o respeito à soberania e aos benefícios econômicos recíprocos" (Lima, 2013, p. 226).

Dado o protagonismo do Brasil como potência emergente, entende-se a cooperação envolvendo a participação brasileira 
na criação e gestão do Novo Banco de Desenvolvimento (NDB) como um aspecto decisivo da influência do país na tentativa de estabelecer as bases de financiamento de um projeto de poder alternativo regional. Não é de se estranhar, portanto, que, ao trazer o Brasil para o convívio com parceiros asiáticos, em especial a China, e estabelecer uma aliança em moldes de cooperação inusitados, a criação dos BRICS ainda suscita profundas inquietudes no centro do sistema. Os esforços aqui se voltam para a seguinte questão: de que cooperação estamos falando em tempos tão sombrios, particularmente na atualidade brasileira?

A relação comercial da China com a América Latina, sobretudo após a guerra comercial dos EUA com o "Império do Meio”, está passando por alterações devido às pressões e imposições norte-americanas. O caso do Brasil atual (desde 2017) indica uma forte dependência e subordinação política aos Estados Unidos, o que tem gerado incertezas sobre como o país prosperará suas relações com a China.

O Mercosul, como indicado acima, encontra-se em um processo regressivo, uma fase crítica iniciada com a retomada dos governos de direita e relacionada ao que hoje vem se configurando como uma disputa entre a China e os EUA. As relações comerciais entre a China e países da América Latina se intensificaram a partir de 2002, com o ingresso da China na Organização Mundial de Comércio (OMC) e a maior ofensiva comercial chinesa a partir da visita do presidente Hu Jintao à região em 2004, quando dezenas de acordos comerciais, de investimentos e de cooperação foram assinados com diversos países da região. Em 2011, a China exportou para a América Latina mais de US\$ 155 bilhões. Em 2002, do total exportado pelos países da América Latina, 2,1\% foram para a China. Já em 2011, esse número saltou para 9,8\%. No tocante às importações, se em 2002 apenas 4,3\% de tudo que era importado pelos países da região sulamericana vinham da China, em 2011 essa participação 
subiu para $16,4 \%$. O crescimento da participação chinesa nas importações totais dos países do continente aumentou, sem exceção. Em alguns países, a participação chinesa cresceu em mais de 300\% de 2002 para 2011 (Medeiros e Cintra, 2015).

As exportações da América Latina para a China são concentradas em poucas commodities - soja, no Brasil e na Argentina, cobre e madeira, no Chile, minério de ferro no Brasil e petróleo na Venezuela e no Brasil. Em contraste, a elevação da importação das economias latino-americanas tem sido em boa parte de produtos industriais chineses, tanto em bens finais quanto em bens de capital e produtos intermediários (Medeiros e Cintra, 2015). Em 2000, o volume de comércio entre China, América Latina e Caribe foi de 12 bilhões de dólares, enquanto em 2019 já atingia a marca de 315 bilhões de dólares.

\section{Presença diplomática e econômica da China na América Latina}

A disputa geopolítica pela América Latina por parte da China e Estados Unidos no período do governo Trump teve o gigante asiático como maior ganhador e protagonista. A China está tentando ampliar o comércio com a região em US $\$ 500$ bilhões e o investimento estrangeiro em US\$250 bilhões até 2025. O Banco de Desenvolvimento da China (CDB) e o Banco de Exportação e Importação da China (Eximbank) alocam mais recursos para a América Latina do que a soma total oferecida pelo Banco Mundial, Banco Interamericano de Desenvolvimento (BID) e a Corporação Andina de Fomento (CAF) a cada ano (Menezes e Bragatti, 2020).

Segundo Menezes e Bragatti (2020), a intenção do Mercosul de negociar e se aproximar da China é anterior ao período em que o país asiático representava um significativo percentual do comércio dos países membros. 
Os autores citam a XXVI Reunião Ordinária do Conselho do Mercosul, realizada em julho de 2004 em Puerto Iguazú, onde os presidentes reafirmaram seu desejo de aprofundar as relações econômicas e comerciais entre o bloco econômico e a República Popular da China. Nesse sentido, saudou-se a realização do Quinto Diálogo entre ambas as partes em Pequim, onde foi formado um grupo de trabalho para iniciar um estudo de viabilidade sobre um possível acordo de comércio. No entanto, o Mercosul não definiu uma estratégia coletiva para lidar com o gigante chinês.

A relação entre China e Mercosul revela duas tendências: a tendência otimista, que tende a valorizar a relação de complementaridade, uma vez que o aumento da demanda chinesa por matéria-prima contribuiria para o desenvolvimento dos países da região; e a tendência pessimista, que aponta que a China representaria uma ameaça às exportações de produtos manufaturados do sul, onde haveria uma repetição da conhecida relação centro-periferia, dessa vez em relação ao país asiático (Menezes e Bragatti, 2020).

$\mathrm{O}$ investimento direto chinês tem duas características essenciais: a concentração dos investimentos nos setores primário e terciário e a concentração dos investimentos em regiões com abundância de recursos naturais e importantes centros financeiros, como indicam Menezes e Bragatti (2020). Segundo os autores, tais características da política econômica chinesa espelham as tendências comerciais recentes com a crescente integração da produção mundial, por meio de cadeias de valor global em um processo que conecta países desenvolvidos e em desenvolvimento, além de revelar a importância do exponencial aumento de preços de produtos agrícolas e recursos naturais desde os anos 2000. Os principais vetores de investimento estrangeiro são empresas estatais, em setores como petroquímica, energia e mineração, revelando a preferência de investimento do governo chinês. 
Ainda segundo Menezes e Bragatti (2020), desde 2002, ano em que o Estado chinês iniciou uma nova fase de internacionalização das empresas do país, conhecida como going global e aprovada no XVI Congresso do Partido Comunista, a estratégia principal da China é garantir o acesso a recursos naturais através da aquisição de energia e indústrias alimentícias impulsionadas por diplomacia de recursos. Os autores ressaltam que o Estado chinês busca garantir essas fontes através da internacionalização de suas empresas por meio de aquisições nesses dois setores. No entanto, no caso do Brasil, Menezes e Bragatti (2020) apontam que dados da Conferência das Nações Unidas sobre Comércio e Desenvolvimento (UNCTAD) indicam que os investimentos externos chineses, ainda que majoritariamente concentrados em recursos naturais, refletem também novas medidas de política industrial que têm incentivado investimentos em outras atividades, especialmente neste setor.

190 Além de buscar recursos, os autores ressaltam que a China trabalha em duas outras frentes: diversificação de mercado (market hunting) e eficiência, onde o setor automotivo é o que mais tem atraído investimentos chineses no Brasil, podendo contribuir para uma inovação tecnológica no parque industrial do país e na região:

A China, antes focada quase exclusivamente na aquisição de recursos naturais e investimentos nos setores primários, revela sua nova faceta como player global. A diversificação de investimentos traduz na busca de ativos nas áreas de tecnologia, finanças e imobiliário. (Menezes e Bragatti, 2020, p. 456)

Serbin (2019) aponta que uma complexa combinação de fatores, como a crise da globalização, do multilateralismo e da ordem liberal internacional, tem promovido uma reconfiguração profunda na distribuição de poder global 
e um deslocamento da dinâmica econômica do Atlântico à Ásia-Pacífico, com a consolidação progressiva da Grande Eurásia como o novo centro de gravitação global, o que o autor considera representar riscos e oportunidades para a América Latina. Para além do comércio e investimentos, a China tem desenvolvido políticas e ações na esfera diplomática, tornando-se central no desenvolvimento da América Latina e um fator de crescente preocupação para os EUA na região (Serbin, 2019).

Seguindo Serbin (2019), ressaltamos que a China oferece modelos alternativos à democracia liberal, em um contexto de diminuição e decadência do poder dos Estados Unidos e de projeção de novas potências médias, com novas formas de competição geoeconômica e concepções e instituições multilaterais que afetam as existentes. Nesse sentido, o desenvolvimento econômico, político e social se desdobra fragmentado em regiões, afetando a integração e interdependência mundial originalmente gerada pela globalização:

[...] em essência, o processo levanta a possibilidade de uma contradição entre a globalização desenvolvida em termos de comércio de bens, serviços, pessoas e ideias em uma estrutura de crescimento, interdependência e uma desglobalização que se desdobra através uma fragmentação regional, de ordens normativas sobrepostas e de várias dependências. E eventualmente um confronto entre a ordem liberal internacional estabelecida e o surgimento de uma nova ordem eurasiana em potencial. Uma nova proposta que não responde aos valores políticos liberais e visa moldar novas modalidades de governança global menos universal e mais fragmentada; o que coloca em questão a possibilidade de manter as instituições cosmopolitas ou liberais e normas que surgiram no anterior e que apresentam riscos e novos desafios na capacidade de desenvolver alguma forma de governar o mundo. (Serbin, 2019, p. 20) 


\section{A estratégia chinesa}

Em suas relações com a região sul-americana, a estratégia chinesa privilegia acordos e relações bilaterais. No entanto, o país asiático não negligencia aproximações e acordos com organizações e instituições regionais e subregionais, por exemplo, a formalização do Fórum da China com a Comunidade de Estados da América Latina e Caribe (CELAC). Serbin (2019) aponta a preferência chinesa por acordos e relações bilaterais que respondam a um padrão estabelecido pela política externa do país, mas ressaltando que nem todos os países da região têm o mesmo relacionamento ou interesse por parte de Pequim. A assimetria dessas relações econômicas é nítida, visto que nenhum dos países latino-americanos e caribenhos está entre os quinze principais parceiros comerciais da China, ainda que o gigante asiático seja o segundo mais importante para a América Latina e a região figure em segundo lugar em

192 investimentos estrangeiros chineses, depois da Ásia.

Como parte da estratégia chinesa, ainda segundo Serbin (2019), a expansão do BRI (Belt and Road Initiative) para a América Latina tem um componente geopolítico fundamental e se baseia em uma cooperação pragmática de iminência de atividades econômicas com foco no comércio, investimento e desenvolvimento e em conexões que ligam Pequim a uma região fonte de recursos naturais abundantes e investimentos e mercados potenciais. $\mathrm{O}$ autor ressalta que a BRI foi ampliada nos últimos seis anos de duas rotas geográficas para seis terrestres e marítimas, numa projeção global que mais recentemente passou a incluir o alcance ao Ártico e à América Latina e o Caribe, constituindo um componente fundamental do eixo vertical do BRI,

a tal ponto que já em maio 2017, o presidente Xi Jinping classificou a América Latina e o Caribe como 'uma extensão natural da rota marítima da seda' em reunião com 
o Presidente Macri da Argentina durante o Fórum BRI em Pequim. (Serbin, 2019, p. 152)

As principais críticas e preocupações em relação a presença diplomática e econômica da China, especialmente o BRI, foram resumidas em alguns pontos por Serbin: (1) a preocupação com uma potencial "reprimarização" das economias latino-americanas, pelo fato de as exportações destes países para o país asiático serem fortemente baseadas na extração de recursos naturais e commodities; (2) o endividamento crescente dos países da região pelos empréstimos que recebem da China; (3) o impacto no meio ambiente de muitos dos projetos chineses que privilegiam o desenvolvimento econômico acima da preservação; (4) a importação de força de trabalho chinesa para muitos projetos, o que poderia afetar conquistas de direitos trabalhistas locais. $\mathrm{O}$ autor destaca ainda, como um dos maiores exemplos de críticas ao impacto ambiental na América do Sul, um corredor do Atlântico ao Pacífico que passa pela Amazônia e prioriza o desenvolvimento de várias infraestruturas dentro da estrutura do BRI. Foram levantadas suspeitas por observadores e analistas do caráter vago e da falta de transparência da política chinesa e de muitos projetos para a região, que poderiam gerar desmandos e corrupção (Serbin, 2019).

Ao abordar as relações comerciais entre o Mercosul e a China, Bartesaghi (2015) se pergunta se o bloco regional e o gigante asiático seriam sócios para o desenvolvimento. $\mathrm{O}$ autor ressalta que a alta competitividade do setor industrial chinês tem forte impacto no desenvolvimento da indústria regional, especialmente nos níveis de comércio intrarregional. $\mathrm{O}$ autor indica ainda que as relações bilaterais dos países do Mercosul com a China diferem substancialmente, política ou economicamente, impedindo ou dificultando o alcance de posições comuns, o que pode afetar o aprofundamento das relações regionais. Assim, os 
impactos da penetração de produtos industriais chineses depende das características das economias nacionais dos parceiros do Mercosul - produção interna -, afetando fortemente as trocas regionais que tenham componente intra-industrial, ao contrário do que acontece com as exportações extrazona desses países - com base em produtos primários e agroindustriais.

O comércio entre Mercosul e China tem sido definido como complementar: o país asiático exporta, principalmente, bens industrializados com alto processo e conteúdo tecnológico e importa, principalmente, produtos agrícolas e recursos naturais. No entanto, tal comércio com pouco componente intra-industrial parece reforçar o baixo vínculo produtivo dos países do Mercosul com a China, quando comparados aos fluxos de comércio que o país asiático tem com as potências desenvolvidas ou com os países da Associação de Nações do Sudeste Asiático (ASEAN) (Bartesaghi, 2015).

194 A China teve uma penetração regional significativa nos últimos anos, em categorias onde há importantes níveis de comércio inter-regional e intra-industrial entre Brasil e Argentina, principais sócios no Mercosul.

Entre 2001-2012, a participação da Argentina nas exportações totais do Brasil aumentou um ponto percentual (de 25 para 26\%). Ao contrário, o Brasil é um mercado cada vez menos importante para a Argentina, passando de 23 para $20 \%$ no mesmo período. (Bartesaghi, 2015, p. 169)

Os fluxos comerciais entre a China e o Mercosul nos últimos anos tiveram impactos positivos e negativos, conclui Bartesaghi (2015): se por um lado a demanda crescente de bens primários e agroindustriais (onde o Mercosul tem vantagens de benchmarks), causada pelo crescimento chinês, trouxe crescimento econômico para os países da região, por outro, a indústria regional e os fluxos intrarregionais 
perderam com a competição do país asiático Porém, o autor ressalta que haveria oportunidades a serem desenvolvidas:

Sobre as oportunidades de expansão do comércio com a China, parecem ser mais claramente identificados em produtos agrícolas com maior processo (carne, laticínios, gorduras e óleos), que poderia ser um uma indicação das oportunidades futuras que existem nos alimentos processados. Novas correntes também são identificadas exportação de bens industriais de conteúdo tecnológico, como plásticos e suas manufaturas, mas ainda em processo de consolidação. (Bartesaghi, 2015, p. 175)

Segundo Bórquez (2020), a abordagem chinesa para a América Latina não concebe a região como uma unidade sócio-política homogênea, pois articula dispositivos de cooperação baseados em perfis de diferentes nações. Assim, ainda de acordo com o autor, a política externa da China não deveria ser medida pelos parâmetros dos EUA para a América Latina, já que Pequim se distancia dos objetivos e normas norte-americanas e a cooperação promovida pela China com países subdesenvolvidos seria baseada no interesse comum, não na promoção de um modelo de governança. $\mathrm{O}$ autor sugere que a ascensão da China tem base em suas capacidades e interesses materiais, mas, por outro lado, suas intenções benignas não seriam mutuamente exclusivas, mas sim dois lados da mesma moeda, onde o país concilia essas duas forças opostas e complementares na execução de suas relações internacionais.

A rede de tratados de livre comércio (TLCs) da China na América Latina, segundo Bórquez (2020), fundamenta-se atualmente em países de médio e pequeno porte localizados na bacia do Pacífico, como Chile, Peru e Costa Rica, de economias complementares e perfil pragmático, ressaltando que os TLCs surgem como ferramentas de uma abordagem 
estratégica mais abrangente, que, além de investimentos, cria condições para promoção de cooperação integral. Outros países, como Argentina, Uruguai e Brasil, indicaram a possibilidade de negociar TLCs com a China (Cucolo, 2019). Nos anos recentes, algumas iniciativas apontaram para a possibilidade de acordo comercial entre o Mercosul e a China (Jornal do Comércio, 2017).

Atualmente, a China tem nove associações estratégicas na América Latina - seis associações estratégicas abrangentes e três associações estratégicas TLC. Bórquez (2020) ressalta que, entre 2001 e 2013, período de boom de investimento chinês na região, a cooperação foi baseada em uma rede de associações estratégicas com países ideologicamente próximos, como Venezuela e Equador, e com as economias industriais emergentes da região, como Brasil e Argentina. O autor destaca que quase metade dos investimentos nos últimos dezesseis anos foram realizados por 196 nove empresas chinesas, com foco em quatro países - Brasil, Argentina, Peru e México -, e os empréstimos concedidos pela China para países como Venezuela, Equador, Argentina e Brasil superaram instituições internacionais como o Banco Mundial (Bórquez, 2020).

Analisando os financiamentos chineses em relações bilaterais na América Latina, Recaj (2020) indica que um pequeno número de países concentra os empréstimos do país asiático: em 2017, assim como no padrão de anos anteriores, Brasil e Argentina, as duas grandes potências sul-americanas, representaram $91 \%$ do total de empréstimos. Para a Venezuela, nem um único dólar chegou do financiamento chinês em 2017, mas em 2016 o país já havia recebido US\$ 2,2 bilhões de empréstimos para infraestruturas petrolíferas e se configura como destino prioritário, ocupando o primeiro lugar entre seus vizinhos em capital emprestado acumulado (Recaj, 2020). Ainda segundo o autor, a China priorizou as relações econômicas bilaterais 
e uma abordagem pragmática com países tanto da Aliança do Pacífico, geopolítica e economicamente mais próximo dos EUA, como do Mercosul, destacando que em termos de comércio, investimento estrangeiro direto e cooperação e empréstimos, os principais destinatários pertencem - Brasil, Argentina, Venezuela - ou estão vinculados - Equador - ao Mercosul. Mas, a China se tornou uma alternativa bancária para países que, por suas políticas macroeconômicas, discurso antineoliberal e tensão com os EUA, se distanciaram das instituições financeiras internacionais (Recaj, 2020).

A China é um grande parceiro comercial dos EUA e o maior detentor oficial de ativos deste país no mundo. $\mathrm{O}$ valor das reservas cambiais chinesas atingiu pouco mais de US\$ 4 trilhões em junho de 2014, mas caiu para US $\$ 3,19$ trilhões em agosto de 2016. O recurso tem que ser aplicado em dólar para não ser desvalorizado, o que tem provocado uma quantidade imensa de projetos tanto no Belt and Road quanto na África e na América Latina. Com relação ao Brasil, entre 2003 e 2017, os chineses investiram em 97 projetos, no valor de US\$ 54 bilhões. Foram anunciados ainda, mas não concretizados, outros 158 projetos, no valor de US\$ 72 bilhões (Boletim dos investimentos chineses no Brasil, CEBC, 2016) Dos investimentos chineses no Brasil entre 2003 e 2017, 68\% estiveram concentrados em quatro setores: extração de petróleo e gás, energia elétrica, extração de minerais metálicos e metalurgia. A maior parte destes investimentos $(72 \%)$ foi feita por empresas de capital público, e a maior parte dos investimentos foi realizada em fusões e aquisições, não em novas plantas produtivas.

Segundo Baumann (2017), deve-se considerar, em relação aos investimentos chineses na América Latina, os seguintes pontos: (1) a concentração chinesa na exploração de recursos naturais, com baixo grau de transformação local; (2) as empresas se apresentam como de capital privado quando são, de fato, de capital público, sendo baixo 
o interesse em investir em setores de tecnologia mais avançada; (3) a crescente participação de investimentos em setores produtores de itens não comercializáveis e que não geram divisas para remunerar o capital.

A China, portanto, é um grande parceiro e investidor no Brasil, mas o último poderia, sobretudo, aprender com a China, que recebeu altos volumes de investimentos de todo o mundo desenvolvido, mas não se subordinou ao capital internacional. Ao contrário, soube incorporar tecnologia externa e aproximar suas indústrias das cadeias de produção internacionais. Esse papel do Estado chinês, tão fundamental para a sua ascensão, pouco foi adotado no Brasil e na América Latina.

A participação brasileira nos BRICS até a deposição da presidenta Dilma Rousseff se apresentava como um projeto auspicioso para o Brasil, reforçado pela criação conjunta do Banco dos BRICS. Hoje, dados os confron198 tos que vêm acontecendo por parte do Brasil e da Índia com os chineses, faz-se necessário avaliar a capacidade emancipatória involucrada nesse ambicioso projeto, cujas principais metas incluíam a reforma do Fundo Monetário Internacional (FMI) e do Sistema Monetário Internacional (SMI), a expansão da cooperação econômica e comercial e o aprofundamento da cooperação nas áreas de saúde, tecnologia e ciência entre seus membros. Essas premissas estão atualmente em suspensão, tendo em vista o desenrolar do novo quadro global.

Finalmente, é importante trazer subsídios para um debate que aponta o vigor com que fatores considerados desestabilizadores da ordem capitalista global resultam em entraves aos projetos tecidos por países tidos como periféricos e do sul. Cabe também notar, sem temer a repetição, que a integração nunca é apenas econômica, jamais é automática ou exclusivamente técnica, e é sempre um processo político, histórico e territorialmente contextualizado. 


\section{Considerações Finais}

Na América do Sul, esboçou-se um projeto de integração ampliada de natureza política, econômica, cultural, geopolítica e social que constituiu uma estratégia coletiva adotada pela expressiva maioria dos governantes de países sul-americanos. Trata-se de uma estratégia de inserir a região no sistema global a partir de sua autonomia, que buscou também promover o desenvolvimento econômico, social e cultural de seus povos. Assim, constitui-se de um projeto cuja natureza política foi explicitada como escolha e orientada para a redução das assimetrias e a superação do lugar de periferia do sistema ao qual a América Latina esteve atada desde seus primórdios.

No plano mais geral da institucionalização, os investimentos no Mercosul foram expandidos visando ao diálogo e à participação de setores organizados da sociedade. No entanto, o bloco se manteve como um processo centralizado nos Estados nacionais que o formam (top-down), vistos como distantes por parte da população (Lima e Bragatti, 2016).

Vitte (2018), a partir da leitura de Vigevani e Ramanzini Júnior (2014), aponta alguns aspectos relevantes da institucionalização da Unasul, concluindo de forma mais geral que na criação deste bloco houve protagonismo do Brasil. Observou ainda que a integração regional ocorrida se deu de forma setorializada, com destaque para a infraestrutura produtiva, a segurança e a defesa e muito pouco com relação concreta ao estabelecimento de um mercado comum. A autora realça ainda que os estados participantes apresentavam orientações político-ideológicas diversas, além de concepções diferenciadas do papel da integração regional em um ambiente regional marcado por forte ativismo presidencial, o que veio a obscurecer a questão sobre a institucionalização da Unasul. Bragatti e Souza (2016) apontam a multidimensionalidade da Unasul como característica marcante do bloco, bem como a baixa institucionalização como germe de 
sua posterior crise, análise compartilhada por autores como Mijares e Nolte (2018) e Sanahuja e Comini (2018).

$\mathrm{O}$ ativismo da política externa brasileira na construção de alianças, preferencialmente com parceiros no âmbito das relações Sul-Sul, resultou na criação de parcerias que se concretizaram com a realização de novos foros, dentre eles a formação do Grupo dos 20 (G20) e do Fórum Trilateral Índia, Brasil e África do Sul (IBAS) (Borges, Lima e Bragatti, 2017). A intensificação da colaboração internacional e a aproximação política com países africanos e asiáticos apontavam para a consolidação da estratégia de expansão e a busca de autonomia do centro do capitalismo.

Como desdobramento, o projeto do Mercosul avançava apesar das fragilidades inerentes ao processo, o que permitiu ao Brasil, país líder do Cone Sul, partir para uma integração também arrojada que foi o processo BRICS, hoje ameaçado. Não será demais lembrar que, a despeito dos enormes 200 desafios e das profundas diferenças internas entre os Estados membros, e sob o impulso do crescente papel exercido pela China, o agrupamento BRICS constituiu um fator-chave na configuração da nova ordem global nos termos propostos pela política externa brasileira altiva e ativa. Tal grupo de países de economias emergentes deve ser analisado dentro de um contexto que Visentini (2005, p. 60) define como:

[...] de afirmação dos interesses dos países em desenvolvimento, de uma tentativa de construir uma ordem internacional multipolar, estruturada a partir da maior atenção aos países em desenvolvimento e baseada no direito internacional e na democracia.

O Brasil, sobretudo pela importância que exerce na América do Sul, assim como os demais países da região, tem muito a aprender com a China. Faz-se necessário que não se reproduzam padrões de dependência, mas que se aproveite 
a capacidade dos investimentos chineses, principalmente em projetos conjuntos associados à revolução 4.0 e aos avanços da ciência e tecnologia, decisivos para o momento de políticas de desindustrialização que o continente atravessa.

Há um conjunto de bons trabalhos - Sanahuja e Comini (2018), Sanahuja (2019), Herrera (2019) e Fernández (2019) -, que explicitam em detalhes o que foi a maré conservadora na região, após 2016:

O ciclo de domínio dos governos progressistas terminou, e a região - com algumas exceções, como a importante mudança política no México - se voltou para a direita, um processo que resultou no surgimento de novos governos liberais-conservadores desde o final de 2015 e, posteriormente, no governo de extrema-direita no Brasil. Também outros governos se aproximaram mais da direita, o que se tornou visível em seus discursos sobre gênero, imigração ou segurança mais conservadores, securitários e punitivistas (Sanahuja 2019, p. 108). ${ }^{10}$

Em 22 de março de 2019, foi estabelecido o Fórum para o Progresso da América do Sul (Prosul) como o novo marco de diálogo político entre governos afins. Embora se postule como uma frente comum de governos democráticos, o Grupo de Lima - com exceção da Costa Rica - se trata de governos liberal-conservadores.

Quais alternativas se colocam às crises sociais e políticas em muitos países da região? As próprias fragilidades apresentadas hoje pelos EUA indicam que esses processos

${ }^{10}$ Original: La etapa dominada por gobiernos progresistas quedó atrás, y la región - con algunas excepciones, entre las que encuentra el importante cambio político de México - ha girado claramente hacia la derecha, en un proceso que desde finales de 2015 ha dado paso a nuevos gobiernos liberal-conservadores y, en momentos posteriores, a un gobierno de ultraderecha en Brasil. También se ha producido un mayor desplazamiento a la derecha de otros gobiernos, lo que se ha hecho visible en sus discursos sobre género, inmigración o seguridad ciudadana, más conservadores, securitarios y punitivistas. (Sanahuja, 2019, p. 108) 
não chegaram a seu termo. Há muito a problematizar e nuançar nessa conjuntura de crises sociais, econômicas e ambientais. Em que medida a disputa sino-americana pode asfixiar a evolução do Mercosul e dos BRICS ou que novas reações advirão das recentes mudanças ocorridas na Bolívia, no Chile e no Peru? Qual a capacidade de irradiação, no contexto regional, na direção de um contramovimento ao conservadorismo, somada à derrota eleitoral de Donald Trump, que por muitos sinalizadores, são questões a serem enfrentadas?

São tempos sombrios. A agenda do final da segunda década do século XXI mudou radicalmente com o retorno do neoliberalismo e o ultraconservadorismo da direita. Aliás, a compatibilidade entre capitalismo e democracia parece cada vez mais remota, como tem sido amplamente observado na literatura. Para Ellen Wood (2003, p. 250), por exemplo:

A lição que talvez sejamos forçados a aprender de nossas atuais condições econômicas e políticas, é que um capitalismo humano, "social" e verdadeiramente democrático e igualitário é mais irreal e utópico do que o socialismo.

São tempos de reflexão. É preciso reagir às tentativas de desmonte do Estado brasileiro e de fragmentação da nossa região. Na linha de estudos que nos ajuda a entender o presente à luz do passado recente, a expectativa é de colaborar para o acúmulo do saber em análises mais robustas que nos permitam superar a perplexidade que nos aparece como crise da esquerda. É necessário ampliarmos o olhar sobre as fronteiras disciplinares, inclusive as impostas às nossas ciências sociais que fragmentam o conhecimento separando, por exemplo, a economia da política, ou a política nacional da internacional. 
São tempos de renovação, de superação da representação política esvaziada mediante a atuação de partidos e movimentos sociais reunidos contra as crescentes opressões econômicas, sociais e culturais do capitalismo global e imperial, e de defesa da democracia.

Por fim, são tempos de resistência contra o retrocesso civilizatório que estamos atravessando, a violência, a agressão econômica e as mentiras midiáticas, como nomeou Boaventura de Souza (2019). Afinal, como já dizia o filósofo Spinoza (1977), o medo sempre leva à tirania. Só a esperança conduz à democracia.

\section{Ingrid Sarti}

Professora Titular de Ciência Política da Universidade Federal do Rio de Janeiro, UFRJ. Foi coordenadora do Programa de Pós-graduação em Ciência Política do Instituto de Filosofia e Ciências Sociais UFCS/UFRJ e professora do Programa de Pós-graduação em Economia Política - Pepi - UFRJ. Doutora pelo Iuperj e Mestre em Ciência Política por Stanford University e Universidade de São Paulo, bacharel em Ciências Sociais pela Universidade de São Paulo, USP.

\section{Marcos Costa Lima}

Professor Associado do Departamento de Ciência Política da Universidade Federal de Pernambuco, UFPE. Possui graduação em Philosophie Politique - Université Montpellier 2 - Sciences et Techniques, mestrado em Sociologia pela Universidade Federal de Pernambuco e doutorado em Ciências Sociais pela Universidade Estadual de Campinas. Pós-Doutorado na Université Paris XIII-Villetaneuse.

\section{Milton Bragatti}

Doutor em Relações Internacionais, Ciências Políticas e Sociais pela Universidade Alma Mater Studiorum de 
Bolonha, UNIBO, Itália, e pela Universidade NOVA de Lisboa, Portugal.

\section{Bibliografia}

AMORIM, Celso. 2020. A integração da América do Sul e a ordem mundial pós-Covid 19. Sul Global, v. 1, n. 2, pp. 8-11.

AURÉLIO GARCIA, Marco. 2017. Retomar el ciclo progresista. Le Monde Diplomatique, edição especial América Latina: Territorio en disputa. Disponível em: https://bit.ly/3j0d0Fs. Acesso em: 18 ago. 2021. BARTESAGHI, Ignacio. 2015. Las relaciones comerciales entre el Mercosur y China, ¿socios para el desarrollo? In: PETERS, Enrique Dussel (coord.). América Latina y el Caribe y China: economía, comercio e inversión 2015. Mexico: Red ALC China. pp. 155-177.

BAUMANN, Renato. 2017. Presença da China: Brasil e América do Sul. 43 slides, Fundação Alexandre de Gusmão. Disponível em: https://bityli. com/2s4YD. Acesso em: 16 ago. 2021.

BOLETIM DOS INVESTIMENTOS CHINESES NO BRASIL (CEBC). 2016. Centro Empresarial Brasil-China. Disponível em: file:// /C:/Users/Acer/AppData/Local/Temp/5.1.\%20 InvestimentosChinesesNoBrasil2016_PT.pdf. Acesso em: 16 ago. 2021. BOAVENTURA DE SOUZA. 2019. Entrevista ao Brasil de Fato. Disponível em: https://www.brasildefato.com.br/2019/01/07/boaventura-e-oscaminhos-da-esquerda-maioria-do-brasil-nunca-viveu-na-democracia.

BORGES, Fabio; LIMA, Marcos Costa; BRAGATTI, Milton Carlos. 2017. Brasil, entre o regionalismo, multilateralismo e relações sul-sul: Política Externa Independente (PEI) no contexto contemporâneo? BRICS, IBAS E UNASUL. In: Repensar las fronteras, la integración regional y el territorio. Costa Rica: CLACSO, IDESPO, Universidad Nacional de Costa Rica. pp. 109-124.

BÓRQUEZ, Andrés. 2020. La red de tratados bilaterales de libre comercio de China como fuente para el desarrollo de iniciativas económicas no tradicionales: teorizando un nuevo marco para analizar la influencia china en América Latina. In: CORTÉS, José Ignacio Martínez (coord.). América Latina y el Caribe - China: relaciones políticas e internacionales 2019. Mexico: Red ALC China. pp. 79-94.

BRAGATTI, Milton Carlos. 2016. Cooperação em defesa na América do Sul: limites e perspectivas. Dissertação de Mestrado em Integração Regional - área de Ciência Política e Relações Internacionais. Foz do Iguaçu: UNILA. 
BRAGATTI, Milton Carlos. 2019. Ten years of the south american defense council: regional international security architecture. Geopolitica(s), Madrid, v. 10, n. 1., pp. 69-86.

BRAGATTI, Milton Carlos. 2020. Theorizing south american international security. Tese de Doutorado em Relações Internacionais. Lisboa: Universidade Nova de Lisboa; Bolonha: Università di Bologna. BRAGATTI, Milton Carlos; SOUZA, Nilson Araújo. 2016. Unasul: iniciativa de integração regional? Instituição de regionalismo pósliberal ou contra-hegemônico? Concertación ou coordenação de interesses comuns? (os debates conceituais sobre um processo em construção). Conjuntura Austral, v. 7, n. 35, pp. 43-51.

BRUCKMANN, Mónica. 2011. Jose Carlos Mariátegui y la producción de conocimiento local. Casa de las Américas, v. 262, pp. 121-123.

CARVALHO, Glauber Cardoso. 2018. As idas e vindas do processo de integração regional na América do Sul: a Unasul e a bonança entre tempestades. Tese de Doutorado em Economia Política Internacional. Rio de Janeiro: UFRJ.

CUCOLO, Eduardo. 2019. Acordo de livre-comércio entre Brasil e China depende de parceiros do Mercosul. Folha de S. Paulo, 13 nov. 2019. Disponível em: https://bityli.com/MANIT. Acesso em: 18 ago. 2021.

CUNHA, Guilherme L. 2017. As relações Brasil-China: ciência, tecnologia e inovação no século XXI. Tese de Doutorado em Economia Política Internacional. Rio de Janeiro: UFRJ.

FERNÁNDEZ, Aníbal García. 2019. El Prosur para la desintegración regional. Página 12, 31 mar. 2019. Disponível em: https://bityli.com/ FX11J. Acesso em: 18 ago. 2021.

FUCCILLE, Luís Alexandre; BRAGATTI, Milton Carlos; LEITE, Maria Luísa Telarolli. 2018. Geopolítica dos recursos naturais na América do Sul: um panorama dos recursos hídricos sob a ótica da segurança internacional. Mural Internacional, v. 8, n. 1, pp. 59-75.

FUCCILLE, Luís Alexandre. 2018. A integração sul-americana em defesa: a liderança do Brasil e suas contradições. In: PENNAFORTE, Charles Pereira; MARTINS, Marcos Antônio Fávaro (org.). Dimensões da integração regional: uma perspectiva panorâmica. Pelotas: Editora UFPel. pp. 24-33.

FUKUSHIMA, Kátia Alves. 2019. Os impasses à democracia participativa nos governos de esquerda: os casos do Brasil, do Chile e da Venezuela. Colombia Internacional, n. 98, pp. 105-135.

GONÇALVES, Williams. 2017. Autonomia. In: CARVALHO, Glauber; ROSEVICS, Larissa (org.). Diálogos internacionais: reflexões críticas do mundo contemporâneo. Rio de Janeiro: PerSe. pp. 47-60. 
GUIMARÃES, Cesar. 2008. Integração hemisférica ou integração autônoma. In: LIMA, Maria Regina (org.). Desempenho de governos progressistas no Cone Sul: agendas alternativas ao neoliberalismo. Rio de Janeiro: IUPERJ. pp. 239-247.

GUIMARÃES, Samuel Pinheiro. 2002. Quinhentos anos de periferia: uma contribuição ao estudo da política internacional. 4. ed. Porto Alegre: UFRGS; Rio de Janeiro: Contraponto.

HERRERA, Juan C. 2019. Prosur: el nuevo mecanismo para no integrar a Latinoamérica. The New York Times, 9 abr. 2019. Disponível em: https://nyti.ms/3ggFsRS. Acesso em: 18 ago. 2021.

HURRELL, A. 2013. The quest for autonomy: the evolution of Brazil's role in the international system, 1964 - 1985. Brasília, DF: Fundação Alexandre de Gusmão.

JAGUARIBE, Hélio. 2008. Brasil, mundo e homem na atualidade: estudos diversos. Brasília, DF: Fundação Alexandre de Gusmão.

JAGUARIBE, Hélio. 2017. Dependencia y autonomía en América Latina. In: JAGUARIBE, Hélio et al. La dependencia político-económica de América Latina. Buenos Aires: CLACSO. pp. 23-80.

JORNAL DO COMÉRCIO. 2017. Mercosul busca negociações de acordo de comércio com China e México. Jornal do Comércio, 13 mar.2017. Disponível em: https://bit.ly/3j25Dxo. Acesso em: 18 ago. 2021. KISSINGER, Henry. 2001. Does America Need a Foreign Policy. Toward a Diplomacy for 21st Century. Nova York: Simon \& Schuster.

LEGLER, Thomas; TURZI, Mariano; TZILI-APANGO, Eduardo. 2020. Advancing autonomy? Chinese influence on regional governance in Latin America. In: BERNAL-MEZA, Raul; XING, Li (ed.). China-Latin America relations in the 21st Century: the dual complexities of opportunities and challenges. Londres: Palgrave-MacMillan.

LIMA, Marcos Costa. 2013. O Brasil, os BRICS e a agenda internacional. In: PIMENTEL, José Vicente de Sá. O Brasil, os BRICS $e$ a agenda internacional. 2. ed. Brasilia: Fundação Alexandre de Gusmão. pp. 221-250.

LIMA, Marcos Costa; BRAGATTI, Milton Carlos. 2016. Tão perto, tão longe: Integração, proximidade e separação na Tríplice Fronteira a percepção do processo de integração regional no coração do Mercosul. In: BENVENUTO, Jayme et al. Somos Todos irmãos? Reflexões sobre a percepção da integração regional na fronteira do Brasil, Argentina e Paraguai. Paraná: GEDAI/UFPR. pp. 90-114.

MARIANO, Karina Pasquariello. 2011. A eleição parlamentar no Mercosul. Revista. Brasileira de Política Internacional, v. 54, n. 2, pp. 138157. Disponível em: https://bit.ly/3CY8bVg. Acesso em: 18 ago. 2021. 
MARIÁTEGUI, J. C. 1928. Siete ensayos de interpretación de la realidad peruana. Lima, Amauta, 1976.

MARTINS, Renato. 2021. Mercosul, 30 anos: a quem interessa a flexibilização do bloco? Carta FoMerco, v. 1, n. 3. Disponível em: https://bit.ly/3sw3Eoc. Acesso em: 18 ago. 2021.

MARX, Karl. 2011. O 18 de brumário de Luís Bonaparte. Boitempo Editorial. MEDEIROS, Carlos A.; CINTRA, Maria Rita. 2015. Impacto da ascensão chinesa sobre os países latino-americanos. Revista de Economia Política, v. 35, n. 1, pp. 28-42. Disponível em: https://bit.ly/3gjx2ZQ. Acesso em: 18 ago. 2021.

MENEZES, Roberto Goulart; BRAGATTI, Milton Carlos. 2020. Dragon in the backyard": China's investment and trade in Latin America in the context of crisis. Brazilian Journal of Political Economy, v. 40, n. 3, pp. 446461. Disponível em: https://bit.ly/3yloDAq. Acesso em: 18 ago. 2021.

MIJARES, Víctor M.; NOLTE, Detlef. 2018. Regionalismo posthegemónico en crisis. Foreign Affairs Latinoamérica, v. 18, n. 3. Disponível em: https://bit.ly/3gjK1e7. Acesso em: 18 ago. 2021.

MORGANTE, Martín Adolfo; CAETANO, Gerardo (org.). 2009.

La reforma institucional del Mercosur: del diagnóstico a las propuestas. Relaciones Internacionales, Montevideo, v. 18, n 37, pp. 1-3.

NERY, Tiago. 2021. A política externa brasileira e a Unasul: geopolítica e expansão do capitalismo brasileiro na América do Sul. Rio de Janeiro: Editora UERJ.

PANIZZA, Francisco. 2006. La marea rosa. Análise de Conjuntura OPSA, n. 8, pp. 1-16.

PENNAFORTE, Charles; MARTINS, Marcos Antonio Fávaro (org.). 2018. Dimensões da integração regional: uma perspectiva. Pelotas: Editora UFPel. PREBISCH, Raúl. 2000. O desenvolvimento econômico da América Latina e alguns de seus problemas principais. In: Bielschowsky, Ricardo. Cinqüenta anos de pensamento na CEPAL. Rio de Janeiro: Record, p. 71-136.

PUIG, Juan Carlos. 1980. Doctrinas internacionales y autonomia

latinoamericana. Caracas: Instituto de Altos Estudios de América Latina, Universidad Simón Bolívar.

QUIJANO, Aníbal. 2005. Colonialidade do poder, eurocentrismo e América Latina. In: LANDER, Edgardo (org.). A colonialidade do saber, eurocentrismo e ciências sociais: perspectivas latino-americanas. Buenos Aires: CLACSO. pp. 117-142.

RECAJ, Carlos M. 2020. El financiamiento chino en América Latina y el Caribe en el contexto de las relaciones económicas bilaterales. In: 
PETERS, Enrique Dussel (coord.). América Latina y el Caribe y China: economía, comercio e inversión. Mexico: Red ALC China, pp. 347-370. RIGGIROZZI, Pia; TUSSIE, Diana. 2018. Claves para leer al regionalismo sudamericano: fortaleciendo el estado, regulando el mercado, gestionando autonomía. Perspectivas, n. 3, pp. 6-21.

ROBERTS, Kenneth M. 2008. ¿Es posible una socialdemocracia en América Latina? Nueva Sociedad, n. 217, pp. 86-98. Disponível em: https://nuso.org/articulo/es-posible-una-socialdemocracia-en-americalatina/. Acesso em: 23 ago. 2021.

SANAHUJA, José Antonio; COMINI, Nicolás. 2018. Las nuevas derechas latinoamericanas frente a una globalización en crisis. Nueva Sociedad, n. 275, pp. 32-46.

SANAHUJA, José Antonio. 2019. La crisis de integración y el regionalismo en América Latina: giro liberal-conservador y contestación normativa. In: MESA, Manuela (coord.). Ascenso del nacionalismo y el autoritarismo en el sistema internacional. Madri: Fundación Cultura de Paz. pp. 107-126.

SARTI, Ingrid. 2011. A projeção do Brasil como ator global e a integração e a integração sul-americana: implicações políticas. In: CAETANO, Gerardo (coord.). Mercosur 20 años. Montevideo: Cefir. pp. 303-320. SARTI, Ingrid. 2014. Integração sul-americana, os desafios de um projeto estratégico. In: SARTI, Ingrid; LESSA, Mônica; MARTINS, José Renato; CARVALHO, Glauber (org.). Os desafios da integração sul-americana: autonomia e desenvolvimento. Rio de Janeiro: Letra e Imagem. pp. 7-12.

SERBIN, Andrés. 2019. Eurásia y América Latina en un mundo multipolar. Buenos Aires: Editorial Icaria-cries.

SPINOSA, Bento de. 1977. Tratado Político. Trad. de Manuel de Castro . Lisboa: Editorial Estampa.

THE ECONOMIST. 2021. The G7 sketches a development-finance initiative to counter China's. The Economist, 12 jun. 2021. Disponível em: https://bityli.com/mAWu9. Acesso em: 18 ago. 2021.

TORRES GARCÍA, Joaquin. 1941. Universalismo constructivo. Buenos Aires: Poseidón.

TORRICO, Gonzalo. 2021. Perú y el Megapuerto de Chancay: la Franja y la Ruta empieza por el mar. Asia Link América Economia, 15 jun. 2021. Disponível em: https://bityli.com/Pvtlv. Acesso em: 23 ago. 2021. VIGEVANI, Tullo; CEPALUNI, Gabriel. 2007. A política externa de Lula da Silva: a estratégia da autonomia pela diversificação. Contexto Internacional, Rio de Janeiro, v. 29, n. 2, pp. 273-335. 
VIGEVANI, Tullo; RAMANZINI JÚNIOR, Haroldo. 2014. Autonomia, integração regional e política externa brasileira: Mercosul e Unasul. Dados, Rio de Janeiro, v. 57, n. 2, pp. 517-552.

VISENTINI, Paulo. 2005. Relações internacionais do Brasil: de Vargas a Lula. 2. ed. São Paulo: Fundação Perseu Abramo.

VITTE, Claudete de Castro. 2018. Institucionalidade da integração regional na América do Sul: o caso da Unasul (união de nações sulamericanas). In: PENNAFORTE, Charles; MARTINS, Marcos Antonio Fávaro (org.). Dimensões da integração regional: uma perspectiva. Pelotas: UFPel. pp. 34-45.

WEYLAND, Kurt. 2009. The rise of Latin America's two lefts: insights from rentier state theory. Comparative Politics, v. 41, n. 2, pp. 145-164.

WOOD, Ellen. 2003. Democracia contra capitalismo: a renovação do materialismo histórico. São Paulo: Boitempo. 
Nuestro norte es el sur 


\section{NUESTRO NORTE ES EL SUR: A BUSCA DA AUTONOMIA, OS DESAFIOS DA INTEGRAÇÃO REGIONAL E A CHINA}

MILTON BRAGATTI

\section{MARCOS COSTA LIMA}

INGRID SARTI

Resumo: A despeito do atual período de ascensão conservadora e plena crise sanitária, política, social, cultural e econômica que assola o continente sul-americano, o Mercado Comum do Sul (Mercosul) completou trinta anos, consolidando-se como bloco regional. Contudo, desarticulado e sob risco de perder os avanços conquistados, o bloco ainda não definiu os rumos para a recuperação ou recriação de uma agenda ampla como a integração do início do século XXI. Este artigo enfatiza a trajetória singular da integração sulamericana a partir de seu caráter original de região periférica do capitalismo e sugere que a conexão entre autonomia, intergovernabilidade e democracia é condição teórica para compreensão. Consideramos a experiência integracionista do sul na agenda progressista de 2005 a 2015, pois esta oferece subsídios para a análise, e refletimos sobre os efeitos do ascenso da aproximação chinesa no continente, em franca disputa com os Estados Unidos.

Palavras-chave: Sul Global; América do Sul; Integração Regional; Autonomia; Desenvolvimento; Democracia; China.

\section{NUESTRO NORTE ES EL SUR: THE QUEST FOR AUTONOMY, THE CHALLENGES OF REGIONAL INTEGRATION, AND CHINA}

Abstract: Despite the current period of conservatism rise and the political, social, cultural, economic, and health crisis that devastates the American continent, the el Mercado Común del Sur (Mercosur) has completed 30 years, consolidating itself as 
a regional bloc. However, disarticulated and at risk of losing its achievements, the Mercosur has not yet defined the paths for the recovery or re-creation of a broad agenda, such as occurred in the beginning of the 21st century. This article emphasizes the singular trajectory of South American integration from its original character as a peripheral region of capitalism, suggesting that the connection between autonomy, intergovernability, and democracy is a theoretical condition for its understanding. Based on the integrationist experience of the South in the 2005-2015 progressive agenda, we will discuss the effects of the rise of Chinese rapprochement on the continent in open dispute with the United States.

Keywords: Global South; South America; Regional Integration; Autonomy; Development; Democracy; China.

Recebido: 14/01/2021 Aprovado: 10/05/2021 